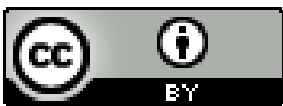

\title{
RELAÇÕES RACIAIS NA ESCOLA: ENTRE LEGISLAÇÕES E COORDENAÇÕES PEDAGÓGICAS
}

\author{
Wilma de Nazaré Baía Coelho ${ }^{1}$ \\ Sinara Bernardo Dias ${ }^{2}$
}

\begin{abstract}
Resumo: Este artigo busca discutir parte das legislações atinentes à diversidade racial na escola, como as Leis $\mathrm{N}^{\circ} 10.639 / 03$ e $\mathrm{N}^{\circ} 11.645 / 08$, a Resolução CNE/CP No 01/2004, o Parecer CNE/CP N ${ }^{\circ}$ 03/2004, as DCNERER, e o Plano Nacional de Implementação destas Diretrizes, assim como evidenciar, por meio da análise documental, conforme Bardin (2016), o papel fundamental das coordenações pedagógicas na efetivação do aparato legal para a educação. Concluímos que a fragilidade do aporte teórico representa o principal entrave para o trabalho da temática pelas coordenações pedagógicas, e que os instrumentos legais evidenciam e reiteram o lugar de definidor de políticas educacionais na escola, como afirmam Coelho e Padinha (2013) e Coelho e Silva (2017).
\end{abstract}

Palavras-chave: Legislações, relações raciais, coordenações pedagógicas, escola básica.

\section{ETHNIC-RACIAL RELATIONS OF SCHOOL: BETWEEN LEGISLATIONS AND PEDAGOGICAL COORDINATION}

Abstract: This article seeks to discuss part of the legislations related to racial diversity inside schools, which are Laws N 10.639 / 03 and N 11.645 / 08, CNE / CP Resolution N 01/2004, DECREE CNE / CP N ${ }^{\circ}$ 03/2004, the national curricular guidelines for the Education of EthnicRacial Relations and the National Plan of Implementation of these guidelines, as well as evidence, through documentary analysis, according to Bardin (2016), referred to those legislations the fundamental role played by pedagogical coordination in implementation of the legal apparatus to the education. We conclude that the frailty of theoretical contribution above is the main obstacle to the work of the subject by pedagogical coordination, and that the legal instruments evidence and reiterate the defining place of educational policy in schools, as stated for Coelho and Padinha (2013) and Coelho e Silva (2017).

Keywords: Legislation, racial relations, pedagogical coordination, school.

\section{RELACIONES RACIALES EN LAS ESCUELAS: ENTRE LEGISLACIONES Y COORDINACIONES PEDAGÓGICAS}

Resumen: Este artículo pretende discutir parte de las legislaciones concernientes a la diversidad racial en las escuelas, como las leyes de número 10.639/03 y 11.645/08, la Resolución CNE/CP

\footnotetext{
${ }^{1}$ Professora Associada IV, Universidade Federal do Pará - UFPA, Faculdade de História, Pesquisadora A2 do CNPq. ORCID: https://orcid.org/0000-0001-8679-809X. E-mail:wilmacoelho@yahoo.com.br

${ }^{2}$ Técnica Pedagógica da Rede Estadual de Ensino - PA e Mestre em Educação Básica - UFPA. ORCID: https://orcid.org/0000-0001-8750-716X.E-mail: naraassistente@yahoo.com.br
}

Revista da ABPN • v.12, $\mathrm{n}^{\mathrm{o}} 32 \cdot$ março - maio 2020, p. 46- 
de número 01/2004, el Parecer CNE/CP de número 03/2004, las DCNERER (Directivas curriculares nacionales para la educación de las relaciones étnico-raciales), y el Plan Nacional de Implantación de estas directivas, así como evidenciar, por medio del análisis documental, teniendo en cuenta Bardin (2016), el papel fundamental de las coordinaciones pedagógicas en la efectuación del aparato legal para la educación. Concluimos que la fragilidad del aporte teórico se configura como la principal traba para el tratamiento de esta temática por las coordinaciones pedagógicas, y que los instrumentos legales evidencian y reiteran el lugar de definidor de políticas educaciones en las escuelas, como afirman Coelho y Padinha (2013) y Coelho y Silva (2017).

Palabras clave: Legislaciones; relaciones raciales; coordinaciones pedagógicas, educación básica

\section{RELATIONS RACIALES À L'ÉCOLE: ENTRE LÉGISLATIONS ET COORDINATION PÉDAGOGIQUE}

Résumé: Cet article traite d'une partie de la législation concernant la diversité raciale à l'école, telles que les lois N 10 639/03 et N 11 645/08, Résolution CNE / CP N 01/2004, Avis CNE / $\mathrm{CPN}^{\circ}$ 03/2004, les DCNERER et le Plan National de mise en œuvre des lignes directrices, comme montrer par l'analyse de documents, selon Bardin (2016), le rôle que les coordinations pédagogiques ont en effectuant l'appareil juridique pour l'éducation.Nous concluons que la fragilité de la contribution théorique représente le principal obstacle au travail du thème par les coordinations pédagogiques et que les instruments juridiques soulignent et réaffirment la place de la définition des politiques éducatives à l'école, comme prétendent Coelho et Padinha (2013) et Coelho e Silva (2017).

Mots-clés: législation, relations raciales, coordination pédagogique, école primaire.

\section{CONSIDERAÇÕES INICIAIS}

As relações raciais no Brasil passaram a ocupar um espaço cada vez maior entre os objetos de estudos de trabalhos científicos, principalmente a partir da promulgação das Leis $N^{o} 10.639 / 03$ e No 11.645/08, que alteram a Lei de Diretrizes e Bases da Educação Brasileira, e obrigam as instituições educacionais a reverem seus currículos. ${ }^{3}$

Neste artigo teremos como objeto as questões tratadas pelas legislações, tais como as Leis $N^{\circ} 10.639 / 03$ e No 11.645/08, a Resolução CNE/CP No 01/2004, o Parecer CNE/CP No 03/2004, as Diretrizes Curriculares Nacionais para a Educação das Relações Étnico-raciais e o Plano Nacional de Implementação dessas Diretrizes, que

\footnotetext{
${ }^{3}$ A quantidade de trabalhos científicos que tratam como tema central a temática da diversidade racial e sua aplicabilidade na educação é destacada por, Lucimar Rosa Dias, Bartolina Ramalho Catanante, Maysa Ferreira da Silva, Wilker Solidade, Josiane Andrade, Thalita Arica (2018), assim como por Petronilha Beatriz Gonçalves e Silva, Nilsa Maria Conceição dos Santos, Rita de Cássia Moser Alcaraz, Roberta Regina Chaves Veloso (2018), embora evidenciem algumas dificuldades como as ações ainda de desenvolverem de forma focalizadas ou a implementação ser entendida como responsabilidade pelo professor, sem articular com as políticas públicas de fomento e implementação, consideram que há avanços com relação à representação da população negra e combate ao racismo.
} 
chamam a atenção para a função da escola ${ }^{4}$ e quanto a importância de trabalhar, entre seus conteúdos, a diversidade racial a partir de referências positivas.

Com o objetivo de destacar as atribuições das coordenações pedagógicas ${ }^{5}$ na efetiva implementação das legislações para o desenvolvimento do respeito à diversidade racial na escola e a importância das legislações para o combate ao racismo e a discriminação, evidenciaremos a relevância destas para a mudança de concepções dos atores educacionais ${ }^{6}$ na educação básica ${ }^{7}$.

Pretende-se, também, relacionar a discussão com a literatura especializada, pois entendemos que torna-se cada vez mais urgente a discussão sobre a atuação dos profissionais da escola e a presença destes nos projetos, planejamentos e demais práticas pedagógicas que envolvam a temática citada, compreendendo que "a educação escolar em uma perspectiva antirracista, não pode ser a transmissão acrítica dos conhecimentos que o Estado e as demais instituições dominantes consideram legítimas, seja por meio do currículo, seja por meio das práticas instituintes na escola" (SANTOS; COELHO, 2016, p. 128). Daí a importância de discutirmos até que ponto as coordenações pedagógicas são mediadoras ou definidoras, como defendem Wilma de Nazaré Baía Coelho Coelho e Maria do Socorro Padinha (2013), de políticas educacionais internas.

Neste artigo reiteramos a importância desses profissionais no lugar de definidores na escola, destacando a convocação feita pelas legislações educacionais para

\footnotetext{
${ }^{4}$ Para Michael Young (2007), é função da escola capacitar os estudantes no sentido de possibilitar que estes apropriem-se dos conhecimentos escolares ou científicos, necessários à compreensão do mundo, a partir da aprendizagem de conceitos aos quais não teria acesso em sua comunidade. José Carlos Libâneo et al (2018) reiteram esta concepção ao defender que a "função da escola é fazer com que as/os discentes não sejam apenas reprodutoras/es de conceitos arcaicos, mas sim formadas/os intelectualmente e socialmente para agir sobre a realidade a qual se vincula." (LIBÂNEO et al, 2018, p. 203).

${ }^{5}$ Utilizaremos a nomenclatura "coordenações pedagógicas", pois apesar de a função receber várias denominações, como técnico pedagógico, especialista em educação, coordenação pedagógica, nas legislações das quais trataremos neste artigo referem-se a estes profissionais daquela maneira.

${ }^{6}$ Ao tratarmos atores educacionais, nos referimos à reflexão de Rui Canário (2005), segundo a qual o uso do termo "nos permite uma visão integrada dos fenômenos individuais e coletivos ao nível de organizações sociais, lugar onde se estabelece a síntese entre as lógicas do sistema e do actor" (CANÁRIO, 2005, p. 121), sendo assim destacamos em nossa discussão os alunos, professores e coordenações pedagógicas e gestão escolar.
}

${ }^{7}$ Segundo a Lei de Diretrizes e Bases da Educação Brasileira, no "Art. 22. A educação básica tem por finalidades desenvolver o educando, assegurar-lhe a formação comum indispensável para o exercício da cidadania e fornecer-lhe meios para progredir no trabalho e em estudos posteriores.". Para Jamil Cury (2008), o conceito de educação básica inovador pois, "como direito, [...] significa um recorte universalista próprio de uma cidadania ampliada e ansiosa por encontros e reencontros com uma democracia civil, social, política e cultural.” (CURY, 2008, p. 294). Neste sentido, a educação básica corresponde a uma etapa fundamental para a formação de cidadãos, sendo nos níveis de ensino que a compõe em que a base de tal cidadania é trabalhada, como destaca Jamil Cury (2008). 
que as suas intervenções pedagógicas abordem as questões relacionadas à diversidade racial, bem como as afirmações feitas em estudos que afirmam que no cotidiano escolar são as coordenações pedagógicas que definem o que deverá ser trabalhado nas salas de aula e fora delas, além de direcionar a rotina da escola e demais ações no espaço escolar (COELHO; SILVA, 2017).

Wilma de Nazaré Baía Coelho e Maria do Socorro Ribeiro Padinha (2013), Wilma de Nazaré Baía Coelho e Carlos Aldemir Farias da Silva (2017) afirmam que as coordenações pedagógicas demonstram diversas dificuldades no desempenho de suas práticas e no trabalho com as questões de diversidade, seja pela fragilidade da formação inicial, pela falta de formação continuada, desconhecimento da literatura especializada e das legislações ou pela grande demanda de atividades diárias.

Para a discussão sobre o cotidiano das coordenações pedagógicas, as questões que fazem parte deste contexto, o trabalho pedagógico com a temática das relações raciais e demais ações essenciais desenvolvidas por elas no direcionamento das atividades da escola, utilizaremos como aporte teórico Vera Maria Nigro de Souza Placco e Laurinda Ramalho de Almeida (2009, 2012, 2015), Wilma de Nazaré Baía Coelho e Maria do Socorro Ribeiro Padinha (2013), Wilma de Nazaré Baía Coelho e Carlos Aldemir Farias da Silva (2017), Sônia Penin (2011).

Ao tratarmos dos textos das normativas consideradas neste artigo recorremos à análise documental proposta por Laurence Bardin (2016), pois segundo a autora esta consiste em tratamento da informação contida nos documentos para "dar forma conveniente e representar de outro modo essa informação, por intermédio de procedimentos de transformação" (BARDIN, 2016, p. 51), sendo assim, a partir dos documentos primários poderá ser possível evidenciar os indicadores que nos permitam inferir sobre a realidade do fazer profissional das coordenações pedagógicas.

As discussões estão organizadas em dois momentos, complementares, o primeiro, com título "Legislação para diversidade racial: a obrigação de tornar visível", discute como as legislações citadas acima determinam e orientam a implementação dos conteúdos referentes à história e a cultura africana, afro-brasileira e indígena nos currículos escolares. E no segundo momento, com título "O papel das Coordenações Pedagógicas", será evidenciado como às coordenações pedagógicas é atribuído o papel de desempenharem ações que promovam a educação para as relações raciais. 


\section{LEGISLAÇÕES PARA DIVERSIDADE RACIAL: A OBRIGAÇÃO DE TORNAR VISÍVEL}

No espaço escolar desenvolve-se uma logística própria, seja por meio da formação de grupos, ou no que diz respeito às relações focadas nas diferenças, sendo estas referentes às questões de pessoas com necessidades especiais, renda, orientação sexual, opção religiosa e/ou raça/cor (COELHO; COELHO, 2013). Sendo assim, mostra-se urgente o aprofundamento teórico sobre as discussões em torno da Lei de Diretrizes e Bases - LDB No 9.394/96 e sua alteração a partir da Lei $N^{\circ} 10.639 / 03^{8}$, que inclui no Currículo Oficial da Rede de Ensino Pública e Privada a obrigatoriedade da temática "História e Cultura Africana e Afro-Brasileira". (COELHO et al, 2014, p. 192)

A Lei $\mathrm{N}^{\circ} 10.639 / 03$ representa uma medida efetiva para o combate à discriminação racial nas escolas brasileiras, pois valoriza a cultura negra e o negro na formação da sociedade nacional, além de evidenciar a participação do povo negro nas áreas social, política e econômica, por meio de práticas educativas baseadas nos objetivos das Diretrizes Curriculares Nacionais para a Educação da Relações ÉtnicoRaciais e Ensino da História e Cultura Afro-brasileira e Africana, que consiste em "[...] corrigir injustiças, eliminar discriminações e promover a inclusão social e a cidadania para todos no sistema educacional brasileiro" (BRASIL, 2004c, p. 5). Sendo assim,

Com a introdução da Lei ${ }^{\circ}$ 10.639/03, o objetivo agora é de ampliar olhares e perspectivas sobre as histórias das muitas Áfricas, já que o continente africano, seus países, povos, culturas, sofreram um profundo processo de achatamento geográfico, reducionismo histórico e invisibilidade de suas comunidades e potencialidades (COELHO et al 2014, p. 59)

Posteriormente, a Lei $\mathrm{N}^{\mathrm{o}} 11.645 / 2008^{9}$, faz referência à temática indígena, com a mesma preocupação em alterar a LDB No 9394/96, garantindo a obrigatoriedade da

\footnotetext{
${ }^{8}$ A Lei altera o Artigo 26-A, que passa ter o seguinte texto: “Art. 26-A. Nos estabelecimentos de ensino fundamental e médio, oficiais e particulares, torna-se obrigatório o ensino sobre História e Cultura AfroBrasileira" (BRASIL, 2003).
${ }^{9}$ Novamente o Artigo 26-A é alterado e adota o seguinte texto: "Art. 26-A. Nos estabelecimentos de ensino fundamental e de ensino médio, públicos e privados, torna-se obrigatório o estudo da história e cultura afro-brasileira e indígena." (BRASIL, 2008). Maria Aparecida Bergamish, Maria Isabel Habckost Dalla Zen, Maria Luisa Merino de Freitas Xavier (2008), Edson Silva, Maria da Penha da Silva (2013), Marcus Vinicius Valente Bararuá, Radanés Aurélio Lima Vale, Mauro Cezar Coelho e Fernando Roque Fernandes (2017), entre outros, afirmam que esta lei repercute de maneira positiva na educação básica, pois dentre suas prerrogativas está a efetivação de encaminhamentos pedagógicos de combate ao preconceito, à discriminação, e à "negação do protagonismo indígena na formação da nacionalidade brasileira” (BARAURÁ; VALE; COELHO; FERNANDES, 2017, p. 63).


inserção da temática nos currículos das instituições educacionais, tornando-se mais um instrumento de orientação para o combate à discriminação étnico-racial de negros e indígenas. Neste sentido, tanto a Lei $\mathrm{N}^{\circ} 10.639 / 2003$, quanto a Lei $\mathrm{N}^{\circ} 11.645 / 2008$, "reconhecem a escola como lugar da formação de cidadãos e afirmam a relevância da escola promover a necessária valorização das matrizes culturais que fizeram do Brasil o país rico, múltiplo e plural que somos”. (BRASIL, 2009, p. 3)

A Resolução CNE/CP No 01/2004 que institui Diretrizes Curriculares Nacionais para a Educação das Relações Étnico-Raciais e para o Ensino de História e Cultura Afro-Brasileira e Africana, surge como uma maneira de orientar as Instituições de ensino, que atuam nos níveis e modalidades da Educação Brasileira e, principalmente, as Instituições que desenvolvem programas de formação inicial e continuada de professores ${ }^{10}$.

Tais Diretrizes são fundamentadas no Parecer CNE/CP No 003/2004, que evidencia as reivindicações e propostas do Movimento Negro ao longo do século XX, e busca direcionar e estimular a elaboração de projetos educacionais que busquem a valorização da história e cultura dos afro-brasileiros e dos africanos, e a construção de referências positivas para a educação das relações raciais. (BRASIL, 2004c)

Sendo assim, no próprio Parecer, consta que devem estar cientes de seu conteúdo os administradores dos sistemas de ensino, de mantenedoras de estabelecimentos de ensino, assim como seus professores a demais profissionais, que são responsáveis pela elaboração, execução, avaliação de programas de interesse educacional, de planos institucionais, pedagógicos e de ensino.

O referido Parecer destaca, desde o tópico “Questões Introdutórias”, o papel fundamental da sociedade de maneira geral, sejam os estudantes, suas famílias ou a comunidade, pois estes, ao terem conhecimento de tal documento, poderão dialogar com os sistemas de ensino, escola e educadores quanto às questões referentes às relações raciais, ao reconhecimento e valorização da história e cultura dos afro-brasileiros e exigir o direito à educação de qualidade, ou seja, não se referindo apenas ao direito de acesso à educação, mas também à formação para a cidadania, com o objetivo de alcançar a construção de uma sociedade justa e democrática.

\footnotetext{
${ }^{10}$ No Artigo $2^{\circ}$ da Resolução, que diz: "Art. $2^{\circ}$ As Diretrizes Curriculares Nacionais para a Educação das Relações Étnico-Raciais e para o Ensino de História e Cultura Afro-Brasileira e Africanas constituem-se de orientações, princípios e fundamentos para o planejamento, execução e avaliação da Educação, e têm por meta, promover a educação de cidadãos atuantes e conscientes no seio da sociedade multicultural e pluriétnica do Brasil, buscando relações étnico-sociais positivas, rumo à construção de nação democrática.", fica claro o caráter de direcionamento que busca-se com o referido documento.
} 
No tópico específico, "Educação das relações étnico-raciais", contido no Parecer tratado, o trabalho de reeducação para as relações raciais não é obrigação exclusiva da escola, mas esta "tem papel preponderante para eliminação das discriminações e para emancipação dos grupos discriminados" (BRASIL, 2004a, p. 6), daí a necessidade de um trabalho pedagógico que não pode ser baseado no improviso, como ainda é destacado no mesmo tópico do Parecer. Improviso, no sentido defendido por Wilma de Nazaré Baía Coelho e Mauro Cézar Coelho (2010), que afirmam referir-se à "ausência de preparação" (COELHO; COELHO, 2010, p. 109), considerando o conhecimento pedagógico e a experiência, no entanto, os autores constatam que o improviso assume um lugar estrutural nas ações dos profissionais da educação, pois em suas pesquisas

professores e técnicos deixaram evidente que as premissas que organizam as perspectivas de aprendizagem, a organização e a exposição de conteúdos e a relação com os alunos não têm relação direta e necessária com o conhecimento sistematizado sobre psicologia da aprendizagem, os mecanismos de transposição didática e as relações interpessoais da Escola (COELHO; COELHO, 2010, p. 122).

Este tipo de atitude dificulta a efetivação das legislações tratadas neste artigo e diante das inquietações geradas pela promulgação da Lei $N^{\circ} 10.639 / 03$, com relação à sua aplicabilidade, o Parecer CNE/CP No 003/2004 busca oferecer caminhos para a área da educação, quanto à essa demanda, no sentido de políticas de ações afirmativas ${ }^{11}$, ou seja, de políticas de reparação, e de reconhecimento e valorização de sua história, cultura e identidade, pois nele encontramos orientação para elaboração de política

\footnotetext{
${ }^{11}$ Para Thais Santos Moya, Valter Roberto Silvério (2009) as ações afirmativas surgem no Brasil, por meio da mobilização do movimento negro e da sociedade civil organizada, como uma "possibilidade política de transformar esse sistema que impede que determinadas pessoas tenham acesso a locais e cargos de poder, em razão de estarem alocadas em posições ou grupos concebidos socialmente como inferiores. A ação afirmativa é uma atitude política que resulta à compreensão analítica de que o acesso ao poder e a completa cidadania dos indivíduos foram cerceados da maioria deles, exatamente porque, na prática, estes não são reconhecidos e tratados como tais. Ou seja, os processos simbólicos resultantes do racismo, do sexismo, do regionalismo, da homofobia, etc. despiram a individualidade daqueles enquadrados como desviantes do padrão eurocentrado e consolidaram-nos coletivamente" (MOYA; SILVÉRIO, 2009, p. 247). Portanto, como evidencia Andréa Lopes da Costa Vieira (2003), as políticas de ações afirmativas vão desde combater a desigualdade socioeconômica entre brancos e negros, até estabelecer punições aos que adotarem práticas discriminatórias, ou seja, referem-se ao "conjunto de ações compensatórias [como as cotas nas universidades e concursos públicos] concentra suas forças na tentativa de correção da situação de desvantagem imposta aos negros historicamente e, em uma última instância, está direcionado para a promoção de uma sociedade democrática, a qual não pode ser atingida sem a igualdade." (VIEIRA, 2003, p. 86). Segundo João Feres Junior (2006), para as políticas de ações afirmativas a "justiça social deveria ter papel justificativo preponderante, secundada pela reparação, enquanto a diversidade não deveria ter tanta relevância." (FERES JUNIOR, 2006, p. 55). Siss Ahyas (2014) nos esclarece que, com relação à sua permanência "não se prevê sua implementação por tempo indefinido ou permanente: elas cessam ao atingir as metas a que se propõem alcança" (AHYAS, 2014, p. 183).
} 
curricular fundada em dimensões históricas e sociais que surgiram a partir da realidade brasileira.

Com o objetivo de combater o racismo e as discriminações que atingem particularmente os negros, o Parecer propõe também atitudes e posturas a serem adotadas nas instituições de ensino, ou seja, referindo-se a todos os profissionais da educação responsáveis pelo de desenvolvimento do processo de ensino e aprendizagem, para o reconhecimento e valorização do pertencimento racial seja de descendentes de africanos, povos indígenas, descendentes de europeus e asiáticos. ${ }^{12}$

Entre as metas, o Parecer estabelece a formulação de políticas que tenham como norteador o direito dos negros, assim como de todos cidadãos brasileiros, de cursarem cada um dos níveis de ensino, em escolas com condições estruturais que correspondam à uma educação de qualidade, e que possam ter professores qualificados para trabalhar tanto o ensino de conhecimentos específicos necessário e exigidos na educação formal, como também sejam preparados "para lidar com as tensas relações produzidas pelo racismo e discriminações, sensíveis e capazes de conduzir a reeducação das relações entre diferentes grupos étnico-raciais" (BRASIL, 2004a, p. 2).

Dentre as providências recomendadas pelo Parecer aos sistemas de ensino e estabelecimentos de Educação Básica, nos níveis de Educação Infantil, Ensino Fundamental, Ensino Médio, Educação de Jovens e Adultos e Educação Superior, citamos:

\begin{abstract}
Disponibilização deste parecer, na sua íntegra, para os professores de todos os níveis de ensino, responsáveis pelo ensino de diferentes disciplinas e atividades educacionais, assim como para outros profissionais interessados a fim de que possam estudar, interpretar as orientações, enriquecer, executar as determinações aqui feitas e avaliar seu próprio trabalho e resultados obtidos por seus alunos, considerando princípios e critérios apontados (BRASIL, 2004a, p. 16).
\end{abstract}

Os instrumentos legais que definem as atribuições das instituições e sistemas educacionais quanto às questões da diversidade étnico-racial, como as leis $\mathrm{N}^{\circ}$ 10.639/2003 e No 11.645/2008, o Parecer CNE/CP No 003/2004 e a resolução CNE/CP

\footnotetext{
12 Tais ações são, na verdade, a primeira das determinações do Parecer, de acordo com o seguinte texto: "O ensino de História e Cultura Afro-Brasileira e Africana, evitando-se distorções, envolverá articulação entre passado, presente e futuro no âmbito de experiências, construções e pensamentos produzidos em diferentes e circunstâncias e realidades do povo negro. É um meio privilegiado para a educação das relações étnico-raciais e tem por objetivos o reconhecimento e valorização da identidade, história e cultura dos afrobrasileiros, garantia de seus direitos de cidadãos, reconhecimento e igual valorização das raízes africanas da nação brasileira, ao lado das indígenas, européias, asiáticas." (BRASIL, 2004a, p. 15)
} 
$N^{\circ} 01 / 2004$, orientam as ações neste sentido, por meio da definição das atribuições que cabem às esferas estatais, aos sistemas e estabelecimentos de ensino, professores e coordenações pedagógicas.

No entanto, como consta no Plano Nacional de Implementação das Diretrizes Curriculares Nacionais da Educação para as Relações Étnico-raciais, do ano de 2009, a aplicabilidade das regulamentações ainda precisa ser ampliada nos sistemas de ensino, e para tanto a elaboração do referido Plano torna-se fundamental para que sejam cumpridas as determinações legais, pois

as instituições devem realizar revisão curricular para a implantação da temática, quer nas gestões dos Projetos Políticos Pedagógicos, quer nas Coordenações pedagógicas e colegiados, uma vez que possuem a liberdade para ajustar seus conteúdos e contribuir no necessário processo de democratização da escola, da ampliação do direito de todos e todas a educação, e do reconhecimento de outras matrizes de saberes da sociedade brasileira (BRASIL, 2009, p. 37).

Conforme o $\S 2^{\circ}$, do Art. $3^{\circ}$, da Resolução CNE N 01/2004 constitui o papel das coordenações pedagógicas desenvolver, junto com os professores a Educação das Relações Étnico-Raciais e o estudo de História e Cultura Afro-Brasileira, e História e Cultura Africana, direcionando e discutindo os conteúdos, as competências, as atitudes e os valores, sendo que, ainda no referido Artigo, fica estabelecido que às coordenações pedagógicas atribui-se o perfil de profissional que deverá prover o aprofundamento dos estudos sobre as questões raciais e o desenvolvimento de projetos e programas que envolvam os docentes.

No Parecer CNE $\mathrm{N}^{\circ}$ 03/2004 confere-se às coordenações pedagógicas a atribuição de estabelecer "conteúdos de ensino unidades de estudos, projetos e programas, abrangendo os diferentes componentes curriculares" (BRASIL, 2004a, p. 18), ou seja, História, Geografia, Arte, Língua Portuguesa, Ciências e Matemática, entendendo que a temática das relações raciais transversaliza aos diversos conhecimentos, juntamente com os sistemas e as mantenedoras de ensino.

O Plano Nacional de Implementação das DCNs da Educação para as Relações Étnico-raciais (BRASIL, 2009) tem como objetivo contribuir para que todo o sistema de ensino e as instituições educacionais possam garantir o direito de aprender e a equidade educacional, para o combate ao racismo e à discriminação e contribuir para uma sociedade justa e igualitária. 
Tal objetivo, segundo o próprio Plano, será alcançado por meio da promoção do desenvolvimento de pesquisas e produção de material didático e paradidático que valorizem a cultura afro-brasileira e a diversidade, da colaboração na construção de indicadores que permitam o necessário acompanhamento pelos poderes públicos e sociedade civil, e da efetiva implementação das DCNs da Educação para as Relações Étnico-raciais e para o ensino da história e cultura afro-brasileira e africana.

Trata-se de função do poder público, neste contexto, criar e consolidar agendas propositivas junto à gestores e técnicos das gestões municipais, estaduais e federal, garantindo condições adequadas para seu desenvolvimento como política de Estado e desenvolvendo estratégias para a formação de professores que contemplem as questões da diversidade racial na construção histórica da cultura do país e construção de relações sociais que sejam permeadas pelo respeito.

\section{O PAPEL DAS COORDENAÇÕES PEDAGÓGICAS}

As representações construídas sobre o negro e sua cultura, no interior do ambiente escolar, tanto pode valorizar identidades, diferenças e o respeito à diversidade racial, quanto pode estigmatizá-las, discriminá-las, segregá-las e até mesmo negá-las (GOMES, 2004). A construção de uma identidade negra positiva representa um desafio, principalmente, convivendo e vivendo num imaginário pedagógico que olha e trata os negros e sua cultura de maneira desigual e institucionalizada, pelo menos até antes da Lei $\mathrm{N}^{\mathrm{o}} 10.639 / 03$, e mesmo diante dos avanços que decorrem de tal legislação, as dificuldades ainda se demonstram no cotidiano escolar ${ }^{13}$.

Muitas vezes os estudantes negros são vistos como excluídos, como alguém que, devido ao seu meio sociocultural e ao seu pertencimento racial, já carrega congenitamente alguma dificuldade de aprendizagem e uma tendência a desvios de comportamento, como rebeldia, indisciplina, agressividade e violência. (ROSEMBERG,

\footnotetext{
${ }^{13}$ Retomando o que afirma Michel de Certeau, o cotidiano é o vivido, ou seja, "é aquilo que nos é dado cada dia (ou que nos cabe em partilha), nos pressiona dia após dia, nos oprime, pois existe uma opressão no presente. [...] O cotidiano é aquilo que nos prende intimamente, a partir do interior." (CERTEAU, 1996, p. 31), sendo assim devemos compreender o cotidiano em permanente construção, e ao tratarmos do cotidiano escolar, consideramos as diversas variáveis que interferem na prática dos profissionais da escola (PENIN, 1995), pois, “[...] é na vida cotidiana e a partir dela que se cumprem as verdadeiras criações, aquelas que produzem os homens no curso de sua humanização: as obras" (PENIN, 2011, p. 17).
} 
1987; SOARES, 2005; CARVALHO, 2005; CASTRO E ABRAMOVAY, 2006; COELHO et al, 2014; RODRIGUES; COELHO, 2017; CAVALLEIRO, 2017)

Neste cenário, a responsabilidade de cumprir a lei cabe a todos os atores educacionais, e não apenas ao professor em sala de aula, pois o comprometimento e a orientação, daqueles que compõe a escola e são responsáveis pelo encaminhamento das ações pedagógicas, demonstram-se, cada vez mais, fundamentais.

$\mathrm{O}$ Parecer $\mathrm{CNE} / \mathrm{CP} \mathrm{N}^{\circ}$ 03/2004 esclarece quanto a autonomia dos estabelecimentos de ensino para discutir, propor e efetivar projetos pedagógicos, em cumprimento ao exigido pelo Artigo 26-A da Lei $N^{\circ}$ 9394/96, que foi alterado pela Lei $\mathrm{N}^{\mathrm{o}} 10.639 / 03$ e posteriormente pela Lei $\mathrm{N}^{\mathrm{o}} 11.645 / 08$, e que para tanto podem buscar a colaboração das comunidades a que a escola atende, além de estabelecer canais de comunicação com estudiosos da temática da diversidade racial e do Movimento Negro, para encontrar caminhos e propostas que contemplem a temática, seja no conteúdo das disciplinas ou na vivência da escola.

Dentre os princípios estabelecidos no referido Parecer, para conduzir as ações dos sistemas de ensino, estabelecimentos e professores, o princípio “Ações Educativas de Combate ao Racismo e a Discriminações" encaminha para que as coordenações pedagógicas, juntamente com os orientadores educacionais, professores, representações dos negros e de outras minorias, analisem e reivindiquem que os textos e os materiais didáticos contemplem as discussões sobre diversidade racial, e que assim sejam adotadas providências para corrigi-los.

A partir do que demanda o Art. $3^{\circ}$ da Resolução CNE/CP No 01/2004, os sistemas de ensino, as mantenedoras, a coordenação pedagógica dos estabelecimentos de ensino e os professores, devem estabelecer conteúdos, unidades de estudos, projetos e programas, contemplando as questões da temática das relações raciais, dessa maneira os administradores dos sistemas de ensino e as mantenedoras devem munir os estabelecimentos educacionais com materiais bibliográficos e didáticos.

Conforme o Parecer CNE/CP N 01/2004, atribui-se aos sistemas de ensino, as mantenedoras, a coordenação pedagógica dos estabelecimentos de ensino "acompanhar os trabalhos desenvolvidos, a fim de evitar que questões tão complexas, muito pouco tratadas, tanto na formação inicial como continuada de professores, sejam abordadas de maneira resumida, incompleta, com erros.” (BRASIL, 2004a, p. 18). No referido Parecer, a responsabilidade das coordenações pedagógicas no planejamento de 
atividades $^{14}$, no fomento de discussões e divulgação das questões que contribuam para equidade racial, pode ser evidenciada em alguns momentos, como:

Caberá, aos sistemas de ensino, às mantenedoras, à coordenação pedagógica dos estabelecimentos de ensino e aos professores, com base neste parecer, estabelecer conteúdos de ensino, unidades de estudos, projetos e programas abrangendo os diferentes componentes curriculares (BRASIL, 2004a, p. 18).

Laurinda Ramalho de Almeida e Vera Maria Nigro de Souza Placco (2012) destacam a complexidade da atuação profissional das coordenações pedagógicas, sendo imprescindível no cotidiano deste profissional a mobilização de "uma pluralidade de saberes" (ALMEIDA; PLACCO, 2012, p. 17), sejam eles gerenciais, éticos, políticos, relacionais, curriculares, afetivos, experienciais e profissionais, sem perder de vista a efetivação do processo de ensino e aprendizagem. (ALMEIDA; PLACCO, 2012).

Nas Diretrizes Curriculares Nacionais para a Educação das Relações Étnicoraciais e para o Ensino de História e Cultura Afro-Brasileira e Africana, em seu Art. $3^{\circ}$, que trata da obrigatoriedade da temática ser desenvolvida por meio dos conteúdos, competências, atitudes e valores, a serem estabelecidos e realizados pelas Instituições de ensino e seus professores, com o apoio e supervisão dos sistemas de ensino, entidades mantenedoras e coordenações pedagógicas.

O contato e acompanhamento direto com o efetivo trabalho docente em sala de aula realizado pelas coordenações pedagógicas, pode assumir, a partir do recomendado pelo Parecer CNE/CP No 03/2004, o papel de articulador e mediador, embora, aos analisarmos os documentos aos quais nos referimos, evidencia-se que entre as atribuições destes profissionais está compreendida a definição dos direcionamentos dados ao trabalho pedagógico.

Sendo assim, percebemos no Artigo $3^{\circ}$ das Diretrizes Curriculares Nacionais para a Educação das Relações Étnico-raciais e para o Ensino de História e Cultura AfroBrasileira e Africana, que às coordenações pedagógicas é conferida a seguinte responsabilidade, enquanto obrigação legal:

“§ $2^{\circ}$ As coordenações pedagógicas promoverão o aprofundamento de estudos, para que os professores concebam e desenvolvam unidades de estudos, projetos

${ }^{14}$ Laurinda Ramalho de Almeida e Vera Maria Nigro de Souza Placco (2015), defendem que o planejamento e o desenvolvimento de atividades na escola por parte das coordenações pedagógicas são imprescindíveis para que estes profissionais desempenhem seu papel, levando em consideração a liderança tida como inerente às suas obrigações profissionais. 
e programas, abrangendo os diferentes componentes curriculares." (BRASIL, 2004a, p. 32, grifo nosso).

Logo, percebemos a reiteração de que às coordenações pedagógicas está delegada mais do que a responsabilidade de mediar, mas também a de determinar o direcionamento dado ao currículo dos componentes curriculares, por meio da proposição e planejamento de momentos de estudo e elaboração de ações que promovam a apropriação do aporte teórico sobre a temática.

O Plano Nacional de Implementação das DCNs da Educação para as Relações Étnico-raciais, está dirigido formalmente aos sistemas e instituições de ensino, e orienta para a revisão curricular visando a implantação da temática, quer nas gestões dos Projetos Políticos Pedagógicos ${ }^{15}$, quer nas coordenações pedagógicas e colegiados, visto que possuem autonomia para ajustar os conteúdos cumprir com o que é determinado nas leis citadas acima, efetivando, assim, a ampliação do direito de todos à educação de qualidade que estimule o reconhecimento de outras matrizes de saberes da sociedade brasileira.

No Plano são descritas as atribuições dos atores para a operacionalização da Educação para as relações raciais, entre estes o tópico "5.3 - Atribuições das coordenações pedagógicas.", destaca-se como as coordenações pedagógicas possuem maior interface com o trabalho docente, pois coordena, orienta e supervisiona ações como o plano de curso $^{16}$, plano de aula ${ }^{17}$, projeto político pedagógico.

Tais ações expressam-se como o fundamento das atividades pedagógicas, por isso apresenta grande relevância na intervenção das coordenações, e, ainda segundo o Plano, a estes profissionais cabe a participação nos planejamentos de curso de

${ }^{15}$ Conforme afirma Ilma Passos Alencastro Veiga (2003), o projeto político pedagógico "visa à eficácia que deve decorrer da aplicação técnica do conhecimento. Ele tem o cunho empírico-racional ou políticoadministrativo. Neste sentido, o projeto político-pedagógico é visto como um documento programático que reúne as principais ideias, fundamentos, orientações curriculares e organizacionais de uma instituição educativa ou de um curso", ou seja documento basilar para o direcionamento das atividades pedagógicas. Para José Carlos Libâneo (1993), refere-se ao documento necessário ao estabelecimento de ensino, pois que define objetivos, diretrizes e ações do processo educativo a ser desenvolvido na escola, motivado e direcionado pelas exigências sociais e legais do sistema de ensino e os propósitos e expectativas da comunidade escolar, por meio de princípios pedagógicos, éticos e políticos.

${ }^{16}$ Para a elaboração de um plano de curso é necessário levar em consideração as suas fases: "preparação e apresentação de objetivos, conteúdos e tarefas; desenvolvimento da matéria nova; consolidação (fixação de exercícios, recapitulação, sistematização); aplicação e avaliação" (LIBÂNEO, 2017, p. 241).

17 Para José Carlos Libâneo (2017) o plano de aula é um instrumento que sistematiza todos os conhecimentos, atividades e procedimentos que se pretende realizar numa determinada aula, tendo em vista o que se espera alcançar como objetivos junto aos alunos, trata-se, portanto, um detalhamento do plano de curso, pois organiza a sequência didática efetiva de uma aula. 
aprimoramento, aperfeiçoamento e gestão educacionais. Logo, compete às coordenações pedagógicas tomar conhecimento de tais documentos e legislações, pois estando instrumentalizadas poderão orientar práticas pedagógicas permanentes e planejadas que façam parte das vivências do estabelecimento de ensino, pois como afirma Nilma Lino Gomes (2012):

A sustentabilidade das práticas pedagógicas está estreitamente relacionada com algumas características mais gerais da própria escola: (a) a gestão escolar e de seu corpo docente; (b) os processos de formação continuada de professores na temática étnico-racial; e (c) a inserção no PPP. Não se pode esquecer o peso da cultura escolar, a organização dos tempos e espaços, bem como a materialidade da escola e sua relação com as práticas observadas (GOMES, 2012, p. 30).

Assim, reitera-se que não se refere ao professor como o único responsável por implementar as legislações para diversidade racial, trata-se de uma responsabilidade compartilhada com as coordenações pedagógicas, a gestão escolar e a instituição mantenedora. Mas, como foco deste artigo, destacamos o papel das coordenações pedagógicas, que apresentam suas principais ações definidas no Plano, sendo as seguintes:

a) Conhecer e divulgar o conteúdo do Parecer CNE/CP 03/2004 e a Resolução CNE/CP 01/2004 e da Lei 11645/08 em todo o âmbito escolar;

b) Colaborar para que os Planejamentos de Curso incluam conteúdo e atividades adequadas para a educação das relações etnicorraciais e o ensino de história e cultura afro-brasileira e africana de acordo com cada nível e modalidade de ensino;

c) Promover junto aos docentes reuniões pedagógicas com o fim de orientar para a necessidade de constante combate ao racismo, ao preconceito, e à discriminação, elaborando em conjunto estratégias de intervenção e educação;

d) Estimular a interdisciplinaridade para disseminação da temática no âmbito escolar, construindo junto com professores e profissionais da educação processos educativos que possam culminar seus resultados na Semana de Consciência Negra e/ou no período que compreende o Dia da Consciência Negra (20 de novembro).

e) Encaminhar ao Gestor escolar e/ou aos responsáveis da Gestão Municipal ou Estadual de Ensino, situações de preconceito, racismo e discriminação identificados na escola (BRASIL, 2009, p. 41, grifos nossos).

Portanto, as ações destes profissionais envolvem desde a gestão do ambiente escolar de maneira ampla, quanto o trabalho desenvolvido pelo docente, o andamento do processo de ensino-aprendizagem e a organização de atividades relacionando aos diferentes componentes curriculares. 
A Resolução CNE No 2/2015 trata das novas diretrizes curriculares nacionais para a formação inicial e continuada dos profissionais do magistério da Educação Básica, e como destacam Wilma de Nazaré Baía Coelho e Carlos Silva (2017), nos artigos 3, 5, 8, 12, 13, 14 e 15, desta Resolução,

a prática pedagógica das $\mathrm{CP}$ (coordenadoras pedagógicas) auxilia diretamente na definição das políticas educacionais internas, pois a sua interferência nos procedimentos teóricos e metodológicos costuma ser crucial para a condução do trabalho pedagógico de uma instituição escolar, contribuindo para o enfrentamento da diversidade étnico-racial, sexual e de gênero, formativos e a prática pedagógica (COELHO; SILVA, 2017, p. 89, grifo nosso).

Maria de Nazaré Baía Coelho e Maria do Socorro Padinha (2013, p. 238) afirmam que mesmo as práticas pedagógicas encaminhadas pelas coordenadoras, estejam permeadas pela boa intenção, percebe-se que estas não representam uma mudança efetiva nas situações de discriminação, pois demanda-se um trabalho pedagógico apoiado em referências científicas e o domínio de habilidades técnicas. Portanto, a intervenção das coordenadoras pedagógicas deve ir além de suas vivências pessoais, superar a boa intenção e assumir uma prática a partir de uma intenção teóricoconceitual, pois suas ações precisam ser direcionadas pelo planejamento de atividades que envolvem os docentes, os discentes e suas famílias. Sobre as ações pedagógicas desenvolvidas pelas coordenações pedagógicas, Vera Maria Nigro de Souza Placco e Laurinda Ramalho de Almeida (2009) afirmam que:

o cotidiano do coordenador pedagógico [...] é marcado por experiências e eventos que o levam, com frequência, a uma atuação desordenada, ansiosa, imediatista e reacional, às vezes até frenética... Nesse contexto, suas intencionalidades e seus propósitos são frustrados e suas circunstâncias o fazem responder à situação do momento, 'apagando incêndios' em vez de construir e reconstruir esse cotidiano[...] (PLACCO; ALMEIDA, 2009, p. 47).

Sendo assim, as questões que demandam maiores reflexões e ações planejadas pelas coordenações pedagógicas podem não serem tratadas ou deixadas para depois, devido aos "incêndios" que precisam apagar diariamente. Para evitar que isso aconteça

[...] o conhecimento do cotidiano da escola é necessário por duas razões. Primeiro, porque sendo conhecido é possível conquistá-lo e planejar ações que permitam transformá-lo, assim como lutar por mudanças institucionais no sentido desejado [...] Segundo, porque o cotidiano, sendo conhecido pode fornecer informações a gestões institucionais democráticas que queiram tomar medidas adequadas para facilitar o trabalho ao nível cotidiano das escolas e melhorar a qualidade de ensino aí realizada (PENIN, 2011, p. 161). 
Logo, a importância das coordenações pedagógicas e da apropriação do cotidiano escolar são imprescindíveis, já que as atividades das coordenações pedagógicas são "tanto o planejamento e a manutenção da rotina escolar quanto a formação e o acompanhamento do professor, assim como o atendimento a alunos e pais" (ALMEIDA; PLACCO, 2012, p. 17), ou seja, uma demanda que, sem a devida apropriação teórica e prática, pode causar a sensação de "vazio" das ações.

Laurinda Ramalho de Almeida e Vera Maria Nigro de Souza Placco (2015) afirmam que geralmente "a escola se move no sentido de padronizar, de homogeneizar, de ignorar as diferenças de entrada, e tenta tratar todos os alunos como fossem iguais" (ALMEIDA; PLACCO, 2015, p. 64), mas cabe às coordenações pedagógicas, conforme as legislações abordadas no presente artigo, direcionar atividades pedagógicas que abordem a educação das relações raciais.

O processo de ensino-aprendizagem ${ }^{18}$ corresponde ao principal objeto de trabalho das coordenações pedagógicas, baseadas no currículo formal e nas legislações vigentes, pois tem a função de fomentar tais conhecimento com os agentes escolares. No entanto, percebemos que:

(...) o que impede a institucionalização das políticas afirmativas de promoção da igualdade étnico-racial nas escolas diz respeito às concepções que têm professores e gestores acerca das nossas relações étnico-raciais, pois muitos usam o discurso da 'igualdade' influenciado pelo mito da democracia racial para pasteurizar culturalmente todos os alunos e aí não lidam com a diferença na escola (...) (COELHO et al, 2014, p. 193).

Percebemos, neste contexto, a importância do papel das coordenações pedagógicas, pois,

O trabalho desenvolvido pelas CP (coordenadoras pedagógicas) nas escolas centra-se fundamentalmente em observações do cotidiano escolar e constituemse em ações devidamente articuladas com um ou mais profissionais em relação às sociabilidades adolescentes presentes no espaço escolar, no virtual e na sala de aula, especialmente no tocante às hierarquias constituídas entre eles veladas ou não (COELHO; SILVA, 2017, p. 92).

\footnotetext{
${ }^{18}$ Segundo José Gimeno Sacristán, Angel Ignácio Pérez Gómez (2007) ensino refere-se a "uma atividade prática que se propõe dirigir as trocas educativas para orientar num sentido determinado as influências que se exercem sobre as novas gerações" (SACRSITÁN; GOMEZ, 2007, p. 81). E os mesmo autores conceituam aprendizagem como "um processo de doação de sentido, de significado, às situações em que o indivíduo se encontra. Sob as manifestações observáveis se desenvolvem processos de discernimento e de busca intencional de objetivos e metas. O indivíduo não reage de forma cega e automática aos estímulos e pressões do meio objetivo, reage à realidade tal como a percebe subjetivamente. Sua conduta responde à sua compreensão das situações, ao significado que confere aos estímulos que configuram seu campo vital em cada momento concreto" (SACRSITÁN; GOMEZ, 2007, p. 33).
} 
Logo, a apropriação da temática das relações raciais, o conhecimento das questões relacionadas ao racismo e a formação continuada, são fundamentais para uma prática pedagógica ${ }^{19}$ que resulte na superação do preconceito e da discriminação.

Discutir diversidade e desigualdade na escola não é tarefa fácil, sobretudo na inexistência de repertório teórico-conceitual para o enfrentamento da temática. Quando se pensa em diversidade, pensa-se em negro, mulher, indígena, como se a diversidade se limitasse a esses grupos sociais. Em verdade, todos os grupos devem constituir a diversidade para superar hierarquizações e desigualdades (COELHO; SILVA, 2017, p. 95).

Assim, as coordenações pedagógicas podem planejar e desenvolver atividades que promovam as discussões sobre diversidade, pois a educação pode ser entendida como um amplo processo, constituinte da nossa humanização, que se realiza em diversos espaços sociais: na família, na comunidade, no trabalho, nos movimentos sociais, na escola, dentre outros. O estudos de Wilma de Nazaré Baía Coelho e Carlos Silva (2017), Wilma de Nazaré Baía Coelho e Maria do Socorro Padinha (2013) encontraram conclusões muito próximas, com relação a fragilidades da formação inicial, pois ambos trabalhos afirmam que a formação acadêmica das coordenações pedagógicas não às prepara para a realidade da escola, para as situações de conflito ou discriminação, presentes no cotidiano escolar, e com relação ao conhecimento da literatura especializada, o que afeta estruturalmente as práticas pedagógicas.

Portanto, mesmo a escola sendo um espaço no qual práticas discriminatórias são praticadas, o que faz emergir nos estudantes negros sentimentos como o de inferioridade e de incapacidade, a despeito das propostas de promoção da diversidade, as coordenações pedagógicas podem desempenhar o papel de promover ações que contribuam para a desconstrução dessas visões negativas.

\section{CONSIDERAÇÕES FINAIS}

A discussão a partir da intervenção das coordenações pedagógicas nas questões que envolvem as relações raciais ainda precisam ser aprofundadas, até mesmo para orientar esses profissionais ao desempenharem suas ações, conforme orientam as

\footnotetext{
${ }^{19}$ Wilma de Nazaré Baía Coelho e Maria do Socorro Padinha (2003) entendem prática pedagógica "como empreendimento coletivo dos agentes escolares, professores e, especialmente, coordenadores pedagógicos, que visam garantir não somente a exequibilidade do planejamento e a realização e enraizamento do projeto pedagógico, mas também as filigranas das ações educacionais espraiadas pela sala de aula e que resultam na construção do conhecimento" (COELHO; PADINHA, 2013, p. 231-232).
}

Revista da ABPN・v.12, no $32 \cdot$ março - maio 2020, p. 46-67 
legislações. Na busca da superação das situações de desigualdade e desrespeito à diversidade, as coordenações pedagógicas desempenham um papel fundamental na escola, devido exercer função estratégica na elaboração de ações fundamentadas e propositivas, mas para tanto esses profissionais precisam dominar o repertório teórico referente à questão, assim como das legislações sobre o tema e seu fazer pedagógico.

Nos estudos evidenciados no presente artigo percebemos que, ao observar a escola, as coordenações pedagógicas apresentam pouco conhecimento sobre o referencial teórico e as legislações, além das fragilidades trazidas de sua formação inicial, mesmo sendo o profissional definidor das políticas educacionais internas, ainda não se apropriou desse papel de maneira adequada (COELHO; PADINHA, 2013; COELHO; SILVA, 2017), como orienta, principalmente, o Plano Nacional de Implementação das Diretrizes Curriculares Nacionais para a Educação das Relações Étnico-raciais. Nos tópicos das atribuições e das principais ações recomendadas às coordenações pedagógicas presente no Plano, estes profissionais são chamados à responsabilidade de planejar, garantir e desenvolver políticas de educação para o respeito à diversidade racial.

Portanto, para que os avanços alcançados por meio das Leis, do Parecer e das Diretrizes, que foram tratadas neste artigo, se efetivem nas instituições educacionais, as coordenações pedagógicas estão em posições privilegiadas, tanto para ocupar o lugar de definidoras das políticas educacionais, de acordo com o constatado por Wilma de Nazaré Baía Coelho e Maria do Socorro Padinha (2013), quanto para encaminhar e orientar ações pedagógicas articuladas e interdisciplinares, de acordo com o que lhes são atribuídas legalmente, para que a temática seja algo incorporado à política institucional escolar.

Visto que entre as atribuições e ações que cabem às coordenações pedagógicas, com relação às relações raciais, e os desdobramentos das suas práticas pedagógicas revelam-se como basilares para os procedimentos da escola de maneira geral, e o poder de mobilização e realização desse profissional pode dar legitimidade ao desenvolvimento de ações que contemplem a temática por toda a comunidade escolar.

Sendo assim, as legislações citadas neste trabalho e o fazer profissional das coordenações pedagógicas, juntamente com os demais atores educacionais, como professores, alunos e gestores, apresentam possibilidades de contribuir para a formação de cidadãos sensíveis à diversidade racial, que apresentam potencial para superar as ações isoladas e que podem construir para uma sociedade brasileira em que se 
reconheçam e valorizem as diferenças culturais e sejam possíveis mudanças nas representações sociais dos estudantes negros, a partir de novas práticas pedagógicas orientadas para o enfrentamento da discriminação e do racismo na escola.

\section{REFERÊNCIAS BIBLIOGRÁFICAS}

ALMEIDA, Laurinda Ramalho de; PLACCO, Vera Maria Nigro de Souza (Org.). $O$ coordenador pedagógico e questões da contemporaneidade. 6 ed. São Paulo: Ed. Loyola, 2012.

ALMEIDA, Laurinda Ramalho de; PLACCO, Vera Maria Nigro de Souza (Org.). $O$ coordenador pedagógico e o atendimento à diversidade. 3 ed. São Paulo: Ed. Loyola, 2015.

AHYAS, Siss. Ações afirmativas, educação superior e neabs: interseções históricas. Cadernos do Centro de Ciências Sociais da Universidade do Estado do Rio de Janeiro, Rio de Janeiro, v. 7, n. 2, 2014, p. 181 - 190. Disponível em: <https://www.epublicacoes.uerj.br/index.php/synthesis/article/view/19667/15087> Acesso em 21 dez. 2019.

BARAURÁ, Marcus Vinicius Valente; VALE, Radanés Aurélio Lima; COELHO, Mauro Cezar. FERNANDES, Fernando Roque. Os povos indígenas como agentes históricos no processo de ensino/aprendizagem. In: COELHO, Wilma de Nazaré Baía; SILVA, Carlos Aldemir Farias da; SOARES, Nicelma Josenila Brito. Relações Étnico-raciais para o ensino fundamental: projetos de intervenção escolar. São Paulo: Livraria da Física, 2017 (Coleção Formação de Professores e Relações Étnico-Raciais).

BARDIN, Laurence. Análise de Conteúdo. Tradução Luís Antero Reto, Augusto Pinheiro. São Paulo: Edições 70, 2016.

BERGAMASCHI, Maria Aparecida; ZEN, Maria Isabel Habckost Dalla; XAVIER, Maria Luisa Merino de Freitas (Org.). Povos indígenas e a educação. Porto Alegre: Mediação, 2008.

BRASIL. Ministério da Educação. Lei N. 9394, de 20 de dezembro de 1996. Estabelece a Lei de Diretrizes e Bases da Educação Nacional, 1996. Disponível em: <http://www.planalto.gov.br/ccivil_03/leis/L9394.htm> Acesso em: 3 set. 2019.

BRASIL. Lei Federal N. 10.639/2003, de 9 de janeiro de 2003. Altera a Lei N. 9. 394, de 20 de dezembro de 1996, que estabelece as diretrizes e bases da educação nacional, para incluir no currículo oficial da Rede de Ensino a obrigatoriedade da temática "História e Cultura AfroBrasileira”, e dá outras providências. Brasília - DF, 2003. Disponível em: <http://www.planalto.gov.br/ccivil_03/leis/2003/L10.639.htm> Acesso em: 3 set. 2019.

BRASIL. Lei Federal N.11645, de 10 de março de 2008. Altera a Lei N. 9.394, de 20 de dezembro de 1996, modificada pela Lei N. 10.639, de 9 de janeiro de 2003, que estabelece as diretrizes e bases da educação nacional, para incluir no currículo oficial da Rede de Ensino a obrigatoriedade de temática "História e Cultura Afro-brasileira e Indígena". Brasília, 2008. Disponível em: 〈http://www.planalto.gov.br/ccivil 03/ Ato2007-2010/2008/Lei/L11645.htm> Acesso em: 4 set. 2019.

BRASIL. Conselho Nacional de Educação. Parecer CNE/CP 3, de 10 de março de 2004. Diretrizes Curriculares Nacionais para a educação das relações étnico-raciais e para o ensino de história e cultura afro-brasileira e africana. Brasília, 2004a. Disponível em: <http://www.mec.gov.br/cne> Acesso em: 21 set. 2019. 
BRASIL. Resolução CNE/CP 01, de 17 de junho de 2004. Diretrizes Curriculares Nacionais para a educação das relações étnico-raciais e para o ensino de história e cultura afro-brasileira e africana. 2004b. Disponível em: http://www.mec.gov.br/cne . Acesso em: 21 set. 2019.

BRASIL. Ministério da Educação. Plano Nacional de Implementação das Diretrizes Curriculares Nacionais da Educação das Relações Étnico-Raciais e para o Ensino de História e Cultura Afro-brasileira e Africana. Brasília, Nov. 2009. Disponível em: $\langle$ http://etnicoracial.mec.gov.br/images/pdf/diretrizes_curric_educ_etnicoraciais.pdf> $>$ Acesso em: 21 set. 2019.

CANÁRIO, Rui. O que é a escola? Um “olhar” sociológico. Porto: Porto Editora, 2005.

CARVALHO, Marília. Quem é negro, quem é branco: desempenho escolar e classificação racial de alunos. Revista Brasileira de Educação, São Paulo, n. 28, jan. - abr., 2005. Disponível em: 〈http://www.scielo.br/pdf/rbedu/n28/a07n28.pdf> Acesso em 12 dez. 2019.

CAVALLEIRO, Eliane. Do silêncio do lar ao silêncio escolar: racismo, preconceito e discriminação na educação infantil. $6^{a}$ ed. São Paulo: Editora Contexto, 2017.

CERTEAU, Michel de; GIARD, Luce; MAYOL, Pierre. A invenção do cotidiano: 2, morar, cozinhar. Petrópolis: Vozes, 1996.

COELHO, Wilma de Nazaré Baía; PADINHA, Maria do Socorro Ribeiro. Coordenadoras e práticas pedagógicas: legislação educacional, formação crítica e relações raciais. Linhas Críticas, Universidade de Brasília - Brasília, v. 19, n. 38, jan. - abr., 2013, p. 229-250. Disponível em: http://www.redalyc.org/pdf/1935/193526311014.pdf. Acesso em: 30 nov. 2018.

COELHO, Wilma de Nazaré Baía; COELHO, Mauro Cezar. Música, raça e preconceito no ensino fundamental: notas iniciais sobre hierarquia da cor entre adolescentes. Afro-Ásia, v. 48, 2013, p. 311-333 Disponível em: $<$ https://www.scielo.br/scielo.php?script=sci_arttext\&pid=S0002-05912013000200009> Acesso em: 27 out. 2019.

COELHO, Wilma de Nazaré Baía; SANTOS, Raquel Amorim dos; SILVA, Rosângela Maria de Nazaré Barbosa; SOUZA, Simone de Freitas Conceição. Lei $N^{o}$ 10.639/2003: Pesquisas e debates. São PAULO: Editora Livraria da Física, 2014. (Coleção Formação de Professores \& Relações Étnico-raciais).

COELHO, Wilma de Nazaré Baía; SILVA, Carlos Aldemir Farias da. Coordenadoras pedagógicas e diversidade: entre percursos formativos e práticas na escola básica. Educar em Revista. Edição Especial, n. 1, 2017, p. 87-102. Disponível em <http://www.scielo.br/scielo.php?pid=S010440602017000500087\&script=sci_abstract\&tlng=pt $>$.Acesso em: 08 out. 2019.

CURY, Carlos Roberto Jamil. A educação básica como direito. Cadernos de Pesquisa, v. 38, n. 134, mai/ago, 2008, p. 293-303 Disponível em: <http://www.scielo.br/pdf/cp/v38n134/a0238134.pdf> Acesso em: 19 dez. 2019.

DIAS, Lucimar Rosa; CATANANTE, Bartolina Ramalho; SILVA Maysa Ferreira da; SOLIDADE, Wilker; ANDRADE, Josiane; ARICA, Thalita. Implementação da lei 10.639/2003. In: SILVA, Paulo Vinícius Baptista da; RÉGIS, Kátia; MIRANDA, Shirley Aparecida de. (Org.). Educação das relações étnico-raciais: o estado da arte. Curitiba: NEABUFPR e ABPN, 2018. p. 147-208. 
FERES JÚNIOR, João. Aspectos normativos e legais das políticas de ação afirmativa. In: FERES JÚNIOR, João; ZONINSEIN, Jonas (Org.). Ação afirmativa e universidade: experiências nacionais comparadas. Brasília: Editora Universidade de Brasília, 2005.

GOMES, Nilma Lino. Juventude, práticas culturais e negritude: o desafio de viver múltiplas identidades. In: REUNIÃO ANUAL DA ANPED, 27, 2004, Caxambu. Anais. Rio de Janeiro: ANPED, 2004.

GOMES, Nilma Lino. (Org.). Práticas pedagógicas de trabalho com relações étnico-raciais na escola na perspectiva da lei $n^{o}$ 10.639/03. Brasília: MEC; Unesco, 2012.

LIBÂNEO, José Carlos. Organização e gestão escolar: teoria e prática. 6 ed. Goiânia: Alternativa, 2017.

LIBÂNEO, José Carlos; ROSA, Sandra Valéria Limonta; SUANNO, Marilza Vanessa Rosa; ECHALAR, Adda Daniela Lima Figueiredo. (Org.). Didática, escola e política: nenhum direito a menos. Goiânia: Gráfica UFG, 2018.

MOYA, Thais Santos; SILVÉRIO, Valter Roberto. Ação afirmativa e raça no Brasil contemporâneo: um debate sobre a redefinição simbólica da nação. Revista Sociedade e Cultura (Impresso), v. 12, 2009, p. 235-249. Disponível em: <https://revistas.ufg.br/fchf/article/download/9097/6271/> Acesso em 21 out. 2019.

PENIN, Sonia. Cotidiano e escola - a obra em construção. 2 ed. São Paulo: Ed. Cortez, 2011. PLACCO, Vera Maria Nigro de Souza; ALMEIDA, Laurinda Ramalho de (Org.). $O$ coordenador pedagógico e o cotidiano da escola. 6 ed. São Paulo, Ed. Loyola, 2009.

RODRIGUES, Anderson Patrick; COELHO, Wilma de Nazaré Baia. Sociabilidades adolescentes na escola básica: estado da arte 2004-2013. Revista Educação (Santa Maria. Online), v. 42, 2017, p. 521-534. Disponível em: <https://periodicos.ufsm.br/reveducacao/article/view/26670> Acesso em: 25 out. 2019.

ROSEMBERG, Fúlvia. Relações raciais e rendimento escolar. Cadernos de Pesquisa, n 63, p. 19-23, nov. $1987 . \quad$ Disponível em: <http://publicacoes.fcc.org.br/ojs/index.php/cp/article/view/1264> Acesso em: 25 out. 2019.

SACRISTÁN, José Gimeno; GÓMEZ, Angel Ignácio Pérez. Compreender e transformar o ensino. 4- ed. Porto Alegre: Artmed, 2007.

SANTOS, Raquel Amorim dos; COELHO, Wilma de Nazaré Baía. Política curricular e relações raciais: o estado da arte nas produções da anped. Revista da Associação Brasileira de Pesquisadores/as Negros/as (ABPN), v. 8, n. 20, out, 2016, p. 111-134. Disponível em: http://abpnrevista.org.br/revista/index.php/revistaabpn1/article/view/12. Acesso em: 15 set. 2019.

SILVA, Edson; SILVA, Maria da Penha da (Org.). A temática indígena em sala de aula: reflexões para o ensino a partir da lei 11.645/2008. Recife: Ed. Universitária da UFPE, 2013.

SILVA, Petronilha Beatriz Gonçalves e; SANTOS, Nilsa Maria Conceição dos; ALCARAZ, Rita de Cássia Moser; VELOSO, Roberta Regina Chaves. Educação das relações étnico-raciais nas instituições escolares. In: SILVA, Paulo Vinícius Baptista da; RÉGIS, Kátia; MIRANDA, Shirley Aparecida de. (Orgs.). Educação das relações étnico-raciais: o estado da arte. Curitiba: NEAB-UFPR e ABPN, 2018. p. 105-146. 
SOARES, Sergei (Org.) Os mecanismos de discriminação racial nas escolas brasileiras. Rio de Janeiro: IPEA, 2005.

VEIGA, Ilma Passos Alencastro. Inovações e projeto político-pedagógico: uma relação regulatória ou emancipatória? Cad. Cedes, Campinas, v. 23, n. 61, dez., 2003, p. 267-281. Disponível em: http://www.scielo.br/pdf/ccedes/v23n61/a02v2361. Acesso em: 15 nov. 2019.

VIEIRA, Andréa Lopes da Costa. Políticas de educação, educação como política: observações sobre a ação afirmativa como estratégia política. In: GONÇALVES, Petronilha Beatriz e Silva; SILVÉRIO, Valter Roberto (Orgs.). Educação e ações afirmativas: entre a injustiça simbólica e a injustiça econômica. Brasília: Instituto Nacional de Estudos e Pesquisas Educacionais Anísio Teixeira, 2003. p. 81-98.

YOUNG. Michael. Para que servem as escolas? Educação e Sociedade, Campinas, 28, nө. 101, set./dez., 2007, p. 1287-1302. Disponível em: <http://www.scielo.br/pdf/es/v28n101/a0228101.pdf> Acesso em: 12 set. 2019.

Recebido 30/03/2020

Aprovado em 30/04/2020 